\title{
Experimental Design Approach for Methylene Blue Dye Removal in Aqueous Environment by Nitrilotriacetic Modified Banana Pith
}

\author{
Shi-Ling Lee, ${ }^{1}$ Shu-Wei Liew ${ }^{1}$ and Siew-Teng Ong ${ }^{1,2, *}$ \\ ${ }^{1}$ Faculty of Science, Universiti Tunku Abdul Rahman, Jalan Universiti, Bandar Barat, 31900 Kampar, Perak, Malaysia \\ ${ }^{2}$ Centre for Biodiversity Research, Universiti Tunku Abdul Rahman, Jalan Universiti, Bandar Barat, \\ 31900 Kampar, Perak, Malaysia \\ *Corresponding author: E-mail: ongst@utar.edu.my; ongst_utar@yahoo.com \\ Tel: 605-4688888; Fax: 605-4661676
}

Received: 21-10-2015

\begin{abstract}
Native banana pith (NBP) was modified by using nitrilotriacetic acid to increase its efficiency and adsorption capacity for methylene blue (MB) dye. The effect of various parameters such as $\mathrm{pH}$, contact time, initial dye concentrations and adsorbent dosage were studied. Equilibrium data could be fitted into Langmuir isotherm and the maximum adsorption capacity of the NBP and NTA-BP is 100 and $142.86 \mathrm{mg} / \mathrm{g}$, respectively. The IR spectrum of NBP and NTA-BP showed the presence of both carboxyl and hydroxyl groups. From the SEM micrographs, the surface morphology of NTA-BP before adsorption appeared to be smoother as compared to that after adsorption process. The $\mathrm{pH}_{\mathrm{pzc}}$ of NBP is 5.6 whereas for NTA-BP is 7.6. The experimental data fitted well into Langmuir isotherm with $\mathrm{R}^{2}$ of 0.992 . Plackett-Burman design was applied to identify the significant factors in affecting the uptake whereas the interaction between the factors and their optimum levels for the maximum percentage uptake of MB were determined using response surface methodo$\operatorname{logy}$ (RSM). Based on the results, the optimum condition for adsorption of MB was by using $0.06 \mathrm{~g}$ of NTA-BP in dye solution at pH 6 with 120 minutes contact time. The maximum adsorption of MB by NTA-BP achieved $99.42 \%$ under the optimum condition.
\end{abstract}

Keywords: Methylene Blue; Banana pith; Adsorption; Plackett Burman; Response surface methodology

\section{Introduction}

Nowadays, dyes are heavily consumed in various industries and there are more than 100,000 commercial dyes with a rough estimated production of $7 \times 10^{5}$ to $1 \times 10^{6}$ tons per year. ${ }^{1-3}$ The source of wastewaters that contain dyes are mainly come from textile industries and followed by paper, plastic and cosmetic industries. However, it is known that 10 to $15 \%$ of the used dyes enter the ecosystem through wastes. ${ }^{4,5}$. Methylene Blue (MB) dye is commonly used in silk fabric, hemp, stained paper dyeing and wood coloring. It is a cationic dye that dissociates into a positively charged component and chloride ion when dissolve in aqueous medium. However, this type of basic dye is generally more toxic than other classes of dyes. ${ }^{6}$ Therefore, the removal of MB from industrial effluents is of utmost importance and can be considered as a challenging problem in the control of environmental pollution as dyes are generally stable to light, oxidizing agent, and are resistant to aerobic digestion. Besides, close study of the dyes has revealed that carcinogenicity is linked to specific types of dye intermediates or metabolites, such as benzidines.

Conventionally, the removal of dyes is achieved either through one or combination of the following methods, biological, chemical and physical treatment. Biological treatment is the most economical among the treatment choices but this method requires a large land area and it is a relatively slow process. ${ }^{7}$ As for the physical and chemical methods, these techniques usually involve expensive instrument or chemical reagent, and often resulted in high sludge production which in turn creates a handling and disposal problem. ${ }^{8}$ In view of the limitations and problems associated with the conventional treatment methods mentioned above, research has therefore been intensified on the utilization and development of low cost materials 
Table 1. Comparison of maximum adsorption capacity for Methylene Blue by various low cost adsorbents

\begin{tabular}{llcr}
\hline Adsorbent & & Maximum adsorption capacity (mg/g) & Reference \\
\hline $\begin{array}{l}\text { Activated carbon } \\
\text { developed from }\end{array}$ & Ficus Carica bast & 47.62 & \\
biomass: & & & {$[9]$} \\
& Salix Psammophila & 501.27 & {$[12]$} \\
& Lantana camara stem & 45.84 & {$[13]$} \\
& Bamboo & 63.5 & {$[14]$} \\
Spent mushroom substrate & & & {$[15]$} \\
Ground palm kernel coat & & 277.77 & {$[16]$} \\
Nitrilotriacetic acid modified banana pith & 142.86 & Current work \\
\end{tabular}

as the potential low cost adsorbents for dye removal. ${ }^{9-11}$ Table 1 shows the maximum adsorption capacity for Methylene Blue by using different types of low-cost materials. The utilization of agricultural by products such as banana pith is of great significance as banana is a widely grown tropical fruits which contributes roughly $16 \%$ of whole fruit production in the world. ${ }^{17}$ The present project aims to modify banana pith with nitrilotriacetic acid to enhance its usefulness and effectiveness for MB removal.

For any adsorption process, there are many important parameters to be considered, such as, $\mathrm{pH}$, initial dye concentration, agitation rate, temperature, contact time and sorbent dosage. The conventional method of investigating a process is by varying one factor while all other factors involved are maintained at constant levels. This is not only time consuming, but also inadequate to describe the combined effect of all the factors involved. Therefore, in this research, study will be extended to include the experimental design involving Plackett Burman and response surface methodology (RSM). Plackett-Burman design composed of a specific fraction $2^{\mathrm{P}}$ factorial design, where the levels of the factors are denoted by +1 (if the factor is at high level) and -1 (if the factor is at low level). Plackett-Burman design is a useful screening tool and it determines the most important variables for further optimization. ${ }^{18}$ As for RSM, it can be used to determine the optimum operational conditions of the system or to determine a region that satisfies the operational specifications. ${ }^{19}$ The applications of such experimental design have also been reported by several authors. ${ }^{20-24}$ It is hope that the incorporation of statistical experimental design in this study can be used to overcome the limitations of a classical method and optimised all the affecting parameters collectively.

\section{Materials and Methods}

\section{1. Adsorbent}

The banana pith (BP) was collected from a residential area in Kampar, Perak and was cut into small pieces and washed several times with tap water before rinsing with distilled water. Then, it was dried at $60{ }^{\circ} \mathrm{C}$ for 48 hours in oven. The dried BP was ground to pass through a $1 \mathrm{~mm}$ sieve and labeled as natural banana pith (NBP). The modification with nitrilotriacetic acid was carried out by treating $5 \mathrm{~g}$ of NBP with $35 \mathrm{~mL}$ of $1.2 \mathrm{M}$ nitrilotriacetic acid trisodium salt monohydrate, ${ }^{25}$ NTA (chemical formula $=\mathrm{C}_{6} \mathrm{H}_{6} \mathrm{NO}_{6} \cdot 3 \mathrm{Na}$, Sigma-Aldrich Pte. Ltd). The treated banana pith was filtered and washed with excess water until neutral before subjected to drying process at $60{ }^{\circ} \mathrm{C}$. The modified material was labeled as NTA-BP.

\section{2. Adsorbates}

Synthetic dye solution of MB (chemical formula $=$ $\mathrm{C}_{16} \mathrm{H}_{18} \mathrm{Cl} \mathrm{N} \mathrm{N}_{3} \mathrm{~S}, \lambda_{\max }=664 \mathrm{~nm}$, molecular weight $=373.90$ $\mathrm{g} / \mathrm{mol}$, C.I. $=52015$ ) from Sigma-Aldrich Pte. Ltd was used as adsorbate in this study. Standard dye solution of 1000 $\mathrm{mg} / \mathrm{L}$ was prepared as stock solution and was diluted accordingly with distilled water to prepare working solution.

\section{3. Instrumental and Characterization Analysis}

The functional groups of NTA-BP before and after adsorption were determined using Perkin Elmer FTIR, Spectrum RX1 at the wavenumber range of $400-4000 \mathrm{~cm}^{-1}$. The sample disk was prepared by mixing the dried sorbent with the KBR. The mixture was then ground and compressed into a pellet before it was analyzed to obtain the spectrum. The surface morphology of the sorbent was studied using field emission scanning electron microscopy (FESEM) which is operated at emission current of $3.0 \mathrm{kV}$ with working distance of $4.6 \mathrm{~mm}$ - JEOL FESEM JSM 6701F. The samples were placed on a stub and coated with a thin layer of gold to prevent the occurrence of charging effect.

\section{4. Batch Study}

All the batch experiments were carried out in duplicate and the results given are the averages. Adsorption experiments were performed by agitating $0.02 \mathrm{~g}$ of adsorbent in $20 \mathrm{ml}$ of dye solution in a centrifuge tube at 150 rpm on an orbital shaker for 4 hours at room temperature 
$\left(25 \pm 2{ }^{\circ} \mathrm{C}\right)$ unless otherwise stated. Control without adsorbent were simultaneously carried out to demonstrate dye uptake was due to adsorbent and not the wall of the centrifuge tube. At the end of the adsorption process, the mixtures were centrifuged at $3000 \mathrm{rpm}$ phase separation. The supernatant was analyzed for its dye concentration using GENESYS 10S single beam UV-Vis spectrophotometer. All the measurements were made at at the wavelength corresponding to maximum absorption, $\lambda_{\max }=664$ $\mathrm{nm}$. Dilutions were carried out when the measurement exceeded the linearity of the calibration curve.

The percentage uptake of MB was calculated by the following equation:

$$
\text { Percentage uptake }=\frac{C_{\mathrm{o}}-C_{\mathrm{e}}}{C_{\mathrm{o}}} \times 100 \%
$$

where $C_{\mathrm{o}}$ and $C_{\mathrm{e}}(\mathrm{mg} / \mathrm{L})$ are the initial and equilibrium liquid phase concentration of $\mathrm{MB}$, respectively.

\section{4. 1. Effect of $\mathrm{pH}$}

MB solutions were prepared in concentration of 100 $\mathrm{mg} / \mathrm{L}$ with initial $\mathrm{pH}$ ranging from $2-10$ by addition of various molarities of hydrochloric acid, $\mathrm{HCl}$ and sodium hydroxide, $\mathrm{NaOH}$ drop wise.

\section{4. 2. Effect of Initial dye Concentrations and Contact Time}

To study the effect of initial dye concentrations and contact time, MB solutions with the concentration of 100 , 150 and $200 \mathrm{mg} / \mathrm{L}$ were prepared. The samples were withdrawn and analyzed for their dye concentrations at predetermined intervals, which are $0.5,1,3,5,10,15,30,60$, $90,120,180$ and 240 minutes.

\section{4. 3. Sorption Isotherm}

Sorption isotherms were obtained by varying the concentration of MB solutions from 100 to $200 \mathrm{mg} / \mathrm{L}$. Then, $0.02 \mathrm{~g}$ of adsorbent was added into $20 \mathrm{~mL}$ of the dye solutions and agitated for 6 hours at $150 \mathrm{rpm}$.

\section{4. 4. Adsorbent Dosage}

The effect of adsorbent dosage was obtained by changing the amount of adsorbent added into the dye solutions from $0.01 \mathrm{~g}$ to $0.06 \mathrm{~g}$.

\section{5. Plackett-Burman Design}

Plackett-Burman design was carried out to study the effect of different variables that affect the uptake of dye. The reason for choosing Plackett Burman is because it enables the experimenters to study a large number of fac- tors with a significantly reduced number of experiment runs. Due to this reason, $\mathrm{PB}$ is often used as a screening tool to identify statistically significant main effects for a large group of experimental factors. ${ }^{18}$ In this analysis, 4 parameters (contact time, initial dye concentration, adsorbent dosage, $\mathrm{pH}$ ) were studied in combination of different experimental conditions generated by Design Expert Version 7.1.3 software. The statistical analysis of the data was carried out using the same software.

\section{6. Response Surface Methodology (RSM)}

The important parameters which affect the percentage uptake of MB were further studied using Response Surface Methodology (RSM) approach. By using central composite design (CCD), the optimum condition for MB removal and the interaction between the variables can be determined. In the analysis, the parameters studied are contact time, adsorbent dosage and $\mathrm{pH}$. Duplications were performed on each experiment and the response is the mean values. Design Expert Version 7.1.3 was used to generate statistical analysis of the data and all the experimental design.

\section{Results and Discussion}

\section{1. Instrumental Analysis}

\section{1. 1. Fourier Transform Infrared Spectroscopy (FTIR)}

Figure 1 shows the infrared spectra of NTA-BP before and after adsorption of MB. The adsorption bands values were compared with those characteristics group absorptions in IR region. It was found that these absorption peaks agreed well with those reported values. ${ }^{26}$ According to the previous findings by Gupta et al., (2011), banana pseudo-stem fibers are rich in cellulose, hemicelluloses and lignin. ${ }^{27}$ Biomass that contains components of cellulose, hemicelluloses and lignin will consist of different oxygen-containing functional groups such as alkene, ester, aromatic, ketone and alcohol. ${ }^{28}$ The IR spectrum of NTA-BP showed the presence of carboxyl and hydroxyl groups. These two functional groups are responsible for the uptake of MB dye due to the negatively charged sites after deprotonation. In aqueous solution, MB dye molecule will dissociate into positively charged component that can be adsorbed by the negatively charged sites. Similarly, banana peel which contains same negatively charge functional groups, carbonyl and hydroxyl groups were reported to be responsible for the uptake of basic dye. ${ }^{29}$ However, the FTIR spectra of NTA-BP before and after adsorption of MB are very similar to each other. This could be due to the limitations in the sensitivity of the instrument. Besides, adsorption itself is a surface chemistry process and therefore, the functional groups that present before and after the process can resemble each other. 


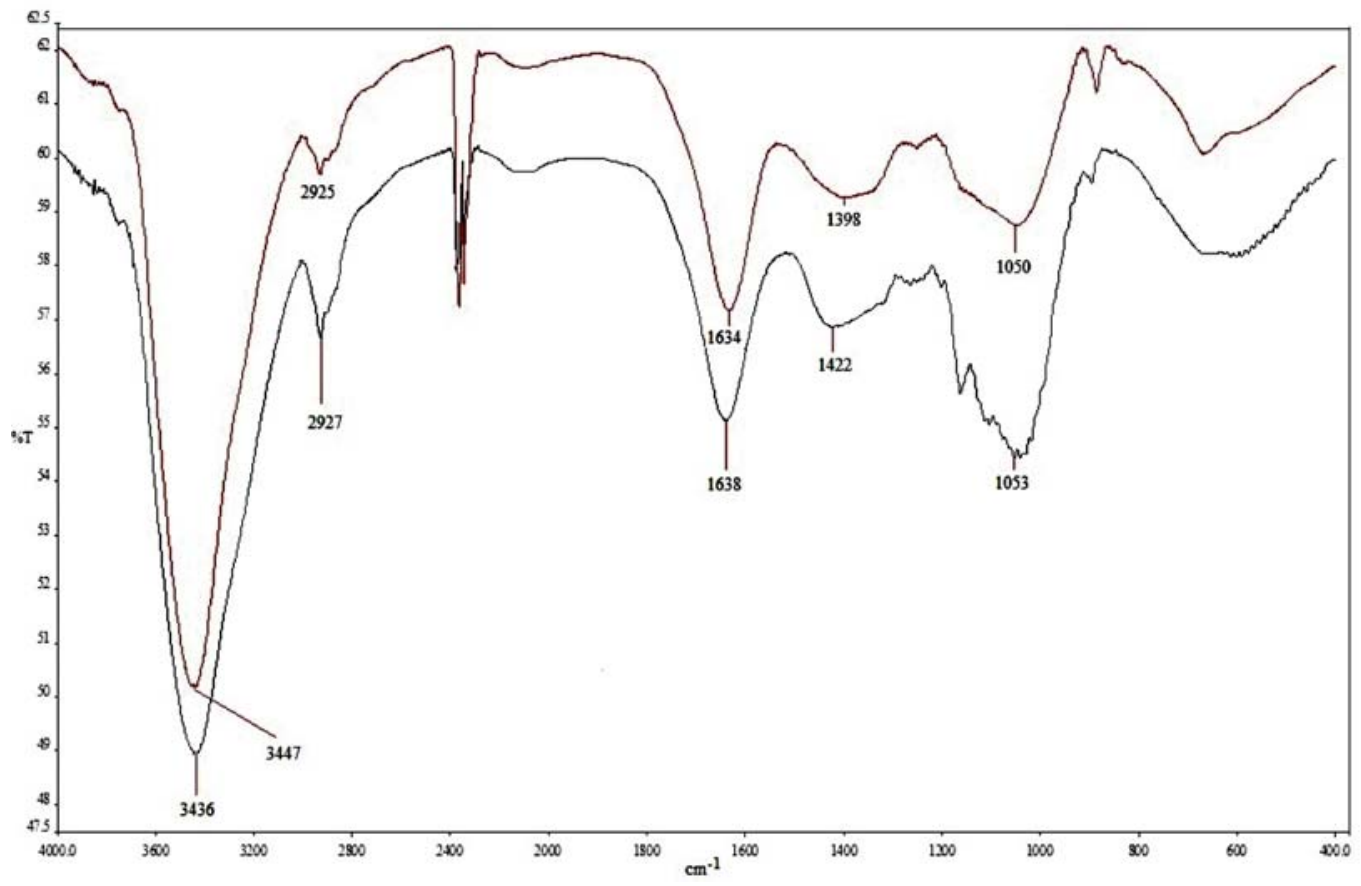

Figure 1. Infrared spectra of NTA-BP before adsorption (bottom) and after adsorption of MB (top)

\section{1. 2. Surface Characterization}

The FESEM micrographs of NTA-BP before and after adsorption are shown in Figures 2(a) and 2(b), res-
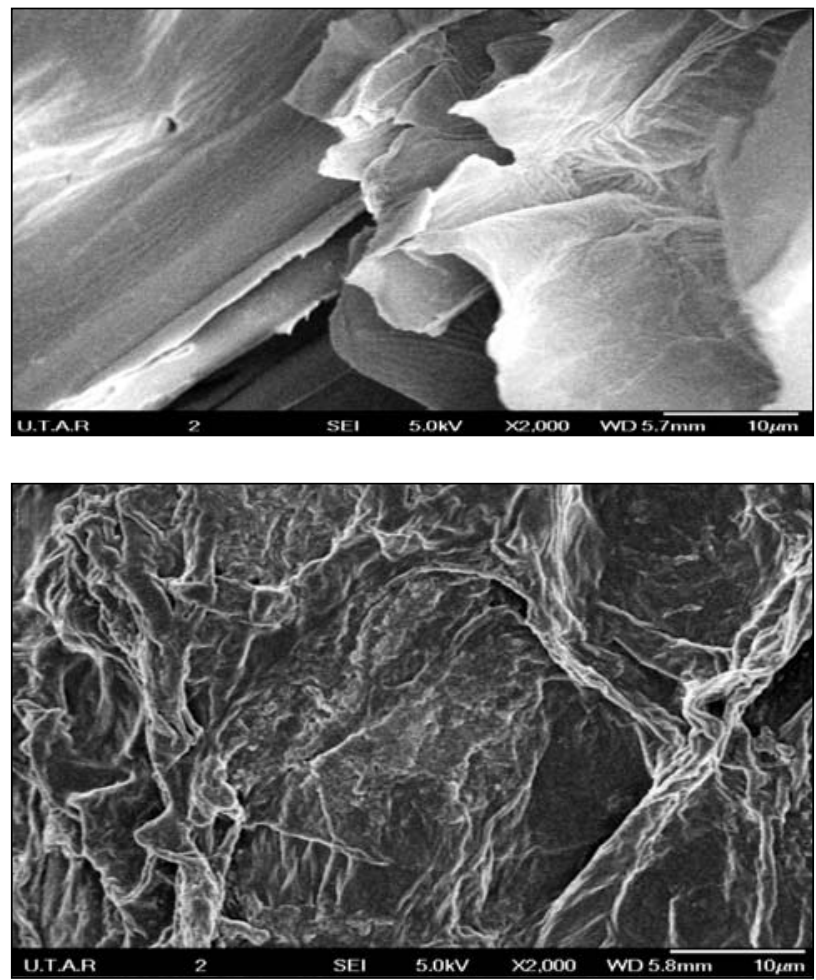

Figure 2. SEM micrographs of NTA-BP (top) before adsorption; (bottom) after MB adsorption pectively. The surface texture of NTA-BP after adsorption appeared to be rougher as compared to that before adsorption. This might imply that the surface of the NTA-BP has been covered with dye molecules. From the micrographs, it can also be noticed that the investigated adsorbent is a non-porous material due to the absence of cavities and pores.

\section{1. 3. Esterification of Carboxylic Groups}

The carboxyl groups in NTA-BP were esterified using acidic methanol method to study the role of carboxyl groups in the adsorption process of MB. If the binding of the dye molecules occurs through the interaction with the carboxyl groups, esterification process will render the carboxyl groups unavailable for the binding due to the formation of methyl ester $\left(-\mathrm{COOCH}_{3}\right)$. This subsequently will result in a reduction of MB uptake. The experimental results obtained agree well with this theory whereby the uptake of MB by NTA-BP were $98.7 \%$ whereas by esterified NTABP was 34.7\% (Figure 3). Similar findings were reported previously in the removal of Basic Blue $3,{ }^{30}$ $\mathrm{Cu}$ and $\mathrm{Pb}{ }^{31}$ The acid esterification process was carried out to block the carboxyl groups which lead to drastic reduction of percentage uptake after this type of modification process. The adverse effect observed in the percentage of uptake proved that carboxyl groups are responsible for the uptake of positively charged species. 


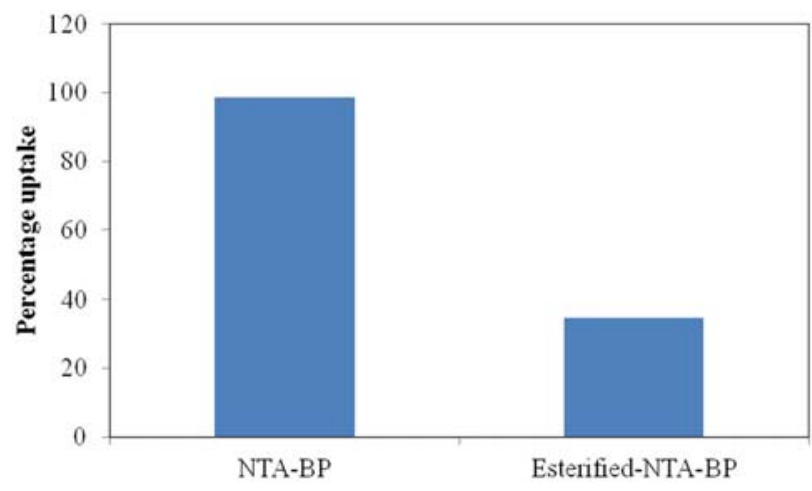

Figure 3. Effect of esterification on the adsorption of MB by NTABP

\section{2. Batch Study}

\section{2. 1. Effect of $\mathbf{p H}$}

Since the efficiency of adsorption process is strongly dependent on $\mathrm{pH}$, which affects the degree of ionization of the adsorbate as well as the surface properties of the adsorbent, comparative experiments were performed at different $\mathrm{pH}$ to show the effect of $\mathrm{pH}$ on the adsorption process of MB on NTA-BP. The influence of initial $\mathrm{pH}$ of dye solution on the uptake of MB by NTA-BP is shown in Figure 4. It can be seen that NTA-BP had a greater uptake capability of $\mathrm{MB}$ from $\mathrm{pH} 4$ onwards. This is due to the phenomenon where the carboxyl groups presence on the surface of adsorbents were predominantly protonated $(-\mathrm{COOH})$ at low $\mathrm{pH}$. Since the carboxyl groups are responsible for binding with $\mathrm{MB}$, protonation of carboxyl groups at low $\mathrm{pH}$ resulted in reduction of adsorption site available for the binding of MB. The adsorption process became favorable with the increasing $\mathrm{pH}$ due to deprotonation of carboxyl groups $\left(-\mathrm{COO}^{-}\right)$. Higher adsorption was facilitated at higher $\mathrm{pH}$ because as the $\mathrm{pH}$ of the system increased, the number of negatively charged sites increased. A negatively charged surface site on the adsor-

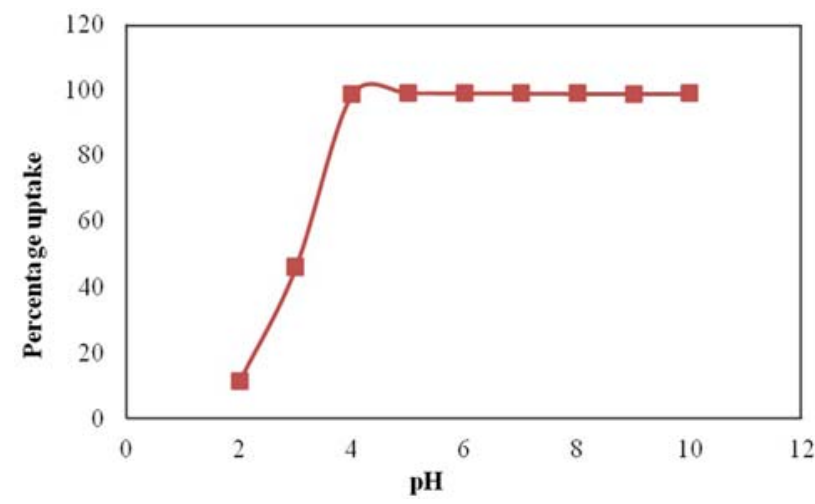

Figure 4. Effect of $\mathrm{pH}$ on the adsorption of MB by NTA-BP (Condition: $0.02 \mathrm{~g}$ of adsorbent in $20 \mathrm{~mL}$ of $100 \mathrm{mg} / \mathrm{L}$ dye solution at $150 \mathrm{rpm}$ for 4 hours). bent favors the adsorption of dye cations due to electrostatic attractions.

\section{2. 2. Effect of Initial Dye Concentrations and Contact Time}

The rates of sorption of MB by NTA-BP at various initial dye concentrations are shown in Figure 5. The result demonstrated that when contact time increased, the uptake of MB increase before the equilibrium is achieved. The percentage of uptake decreased with increasing solution concentration while the amount of dye adsorbed increased. A rapid uptake of dye was observed at the beginning of the process ( $0-25$ minutes) and this may attribute to the fast adsorption of MB molecules on the surface of adsorbent which caused by electrostatic attraction. Besides, the high availability of vacant binding sites on the surface of NTA-BP can also explained the fast uptake at the beginning of the process. With the increasing of time, intraparticle diffusion which slows down the adsorption process occurred, where the adsorbates start to diffuse into adsorbent inner sites.

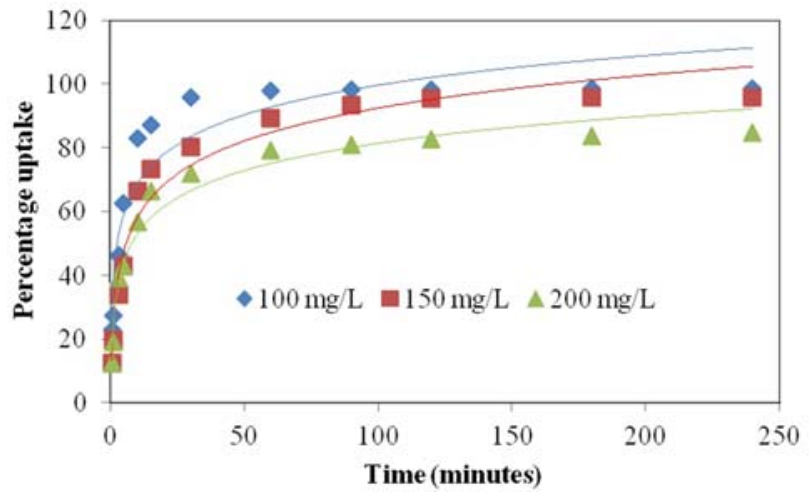

Figure 5. Effect of initial dye concentrations and contact time on adsorption of MB by NTA-BP (Condition: $0.02 \mathrm{~g}$ of NTA-BP in 20 $\mathrm{mL}$ of $\mathrm{MB}$ dye solution at $150 \mathrm{rpm}$ for 4 hours).

\section{2. 3. Sorption Isotherm}

The equilibrium isotherm is important in the design of sorption systems because it can provide some insight into both the sorption mechanisms and the surface properties and affinities of the sorbent. Therefore, the equilibrium sorption data were analysed using two of the most commonly used isotherms equations, Langmuir and Freundlich model. The Langmuir model assumes monolayer coverage of adsorbate over a homogenous adsorbent surface. ${ }^{32}$ Adsorption is assumed to take place at specific homogenous sites on the surface of the adsorbent. Once a sorbate occupies a site, no further adsorption can take place at that site. The equation of Langmuir isotherm was shown below: 


$$
\frac{C_{e}}{q_{e}}=\frac{C_{e}}{q_{m}}+\frac{1}{K_{a} q_{m}}
$$

Notation:

$\mathrm{C}_{\mathrm{e}}=$ Equilibrium liquid phase dye concentration $(\mathrm{mg} / \mathrm{L})$

$\mathrm{q}_{\mathrm{e}}=$ Amount of dye absorbed at equilibrium ( $\left.\mathrm{mg} / \mathrm{g}\right)$

$\mathrm{q}_{\mathrm{m}}=$ Maximum adsorption capacity ( $\mathrm{mg} / \mathrm{g}$ )

$\mathrm{K}_{\mathrm{a}}=$ Adsorption equilibrium constant $(\mathrm{L} / \mathrm{mg})$

The Freundlich isotherm is an exponential equation (Eq. 3) and therefore, assumes that as the adsorbate concentration increases so does the concentration of adsorbate on the adsorbent surface. ${ }^{33}$ Theoretically, using this expression, an infinite amount of adsorption can occur.

$$
N_{e}=K_{f} C_{e}^{n}
$$

where $\mathrm{n}=$ Freundlich constant for intensity and $\mathrm{K}_{\mathrm{f}}=$ Freundlich constant for sorption capacity. Both $\mathrm{n}$ and $\mathrm{K}_{\mathrm{f}}$ can be determined from the plots of $\log \mathrm{N}_{\mathrm{e}}$ versus $\log \mathrm{C}_{\mathrm{e}}$ on the basis of the linear form of the following equation:

$$
\log N_{e}=\frac{\log C_{e}}{n}+\log K_{f}
$$

This expression is characterized by the heterogeneity factor, $\mathrm{n}$ and the Freundlich isotherm can be used to describe heterogeneous surface with a non-uniform distribution of heat adsorption over the surface.

Equilibrium adsorption data of MB on NTA-BP is fitted into both linearized Langmuir and Freundlich equations. The linear plots of $\mathrm{C}_{e} / \mathrm{N}_{\mathrm{e}}$ versus $\mathrm{C}_{\mathrm{e}}$ and $\log \mathrm{N}_{\mathrm{e}}$ versus $\log \mathrm{C}_{\mathrm{e}}$ are shown in Figures 6 and 7, respectively. Although modeling of isotherm data by linear analysis might cause some discrepancy between the predictions and experimental data, the linear forms of the isotherms models are still widely used due to the mathematical simplicity for determining the corresponding isotherm parameters and their correlation coefficients $\left(\mathrm{R}^{2}\right)$. The coefficients for the linearised forms of the isotherm models for the sorption of MB on NTA-BP are listed in Table 2. The maximum adsorption capacity, $\mathrm{q}_{\mathrm{m}}$ for MB is $142.86 \mathrm{mg} / \mathrm{g}$. Based on the correlation coefficients values, $\mathrm{R}^{2}$, Langmuir isotherm was found to be a more suitable model to describe the adsorption of MB on NTA-BP. This type of Langmuir isotherm is one of the most popular linear forms used in literatures, due to the minimal deviations from the fitted equation. ${ }^{34-37}$

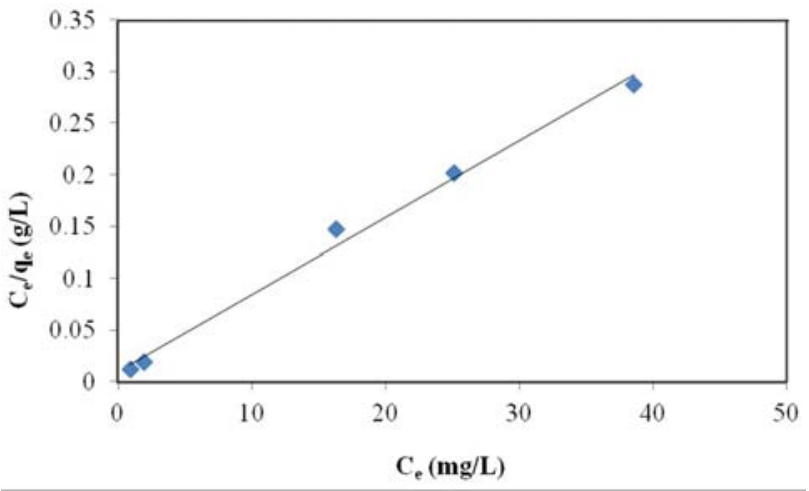

Figure 6. Langmuir isotherm on adsorption of MB by NTA-BP (Condition: $0.02 \mathrm{~g}$ of adsorbent in $20 \mathrm{~mL}$ of 100, 125, 150, 175, $200 \mathrm{mg} / \mathrm{L}$ MB dye solution at $150 \mathrm{rpm}$ for 6 hours).

In Langmuir isotherm, the vital characteristics can be defined using a term known as dimensionless equilibrium parameter, $\mathrm{R}_{\mathrm{L}} \cdot{ }^{38}$ The relationship between $\mathrm{R}_{\mathrm{L}}$ and type of isotherm were shown in Table 3 . The calculated $R_{L}$ value was used to determine whether the adsorption process is unfavourable, linear, favourable, or irreversible. The equation for calculating $\mathrm{R}_{\mathrm{L}}$ value is shown below:

$$
R_{L}=\frac{1}{1+K_{a} C_{o}}
$$

where:

$\mathrm{R}_{\mathrm{L}}=$ Dimensionless equilibrium parameter

$\mathrm{K}_{\mathrm{a}}=$ Adsorption equilibrium constant $(\mathrm{L} / \mathrm{mg})$

$\mathrm{C}_{\mathrm{o}}=$ Initial concentration of dye solution $(\mathrm{mg} / \mathrm{L})$

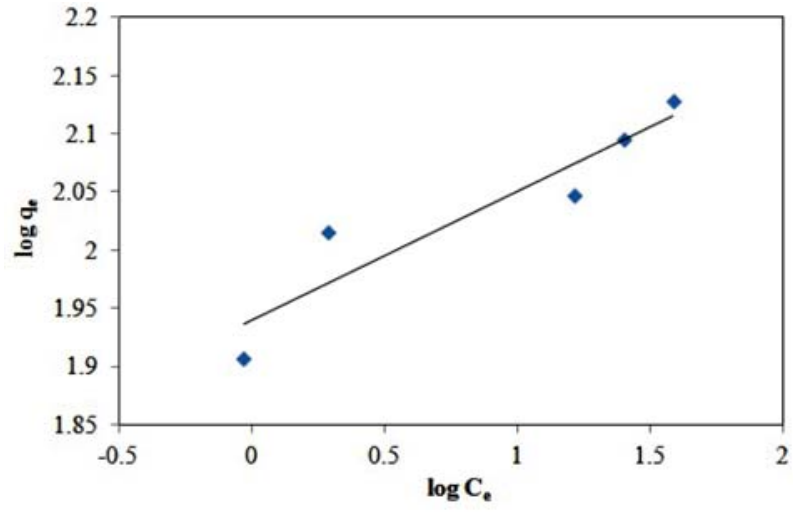

Figure 7. Freundlich isotherm on adsorption of MB by NTA-BP (Condition: $0.02 \mathrm{~g}$ of adsorbent in $20 \mathrm{~mL}$ of 100, 125, 150, 175, $200 \mathrm{mg} / \mathrm{L} \mathrm{MB}$ dye solution at $150 \mathrm{rpm}$ for 6 hours).

Table 2. Langmuir and Freundlich constants for the adsorption of MB on NTA-BP

\begin{tabular}{lcccccc}
\hline \multirow{2}{*}{ Adsorbent } & \multicolumn{3}{c}{ Langmuir } & \multicolumn{3}{c}{ Freundlich } \\
& $\mathbf{q}_{\mathbf{m}}(\mathbf{m g} / \mathbf{g})$ & $\mathbf{K}_{\mathbf{a}}(\mathbf{L} / \mathbf{m g})$ & $\mathbf{R}^{\mathbf{2}}$ & $\mathbf{K}_{\mathbf{F}}$ & $\mathbf{1 / n}$ & $\mathbf{R}^{\mathbf{2}}$ \\
\hline NTA-BP & 142.86 & 0.78 & 0.992 & 86.9 & 0.11 & 0.869 \\
\hline
\end{tabular}


The calculated $R_{L}$ value for NTA-BP of each initial dye concentrations was shown in Table 4. It was evident that all the $\mathrm{R}_{\mathrm{L}}$ values were in the range of $0<\mathrm{R}_{\mathrm{L}}<1$ which indicates the favorable adsorption of MB on NTA$\mathrm{BP}$ under the tested condition.

Table 3. Relationship between $\mathrm{R}_{\mathrm{L}}$ and type of isotherm:

\begin{tabular}{cc}
\hline $\mathbf{R}_{\mathbf{L}}$ & Type of isotherm \\
\hline $\mathrm{R}_{\mathrm{L}}>1$ & Unfavourable \\
$\mathrm{R}_{\mathrm{L}}=1$ & Linear \\
$0<\mathrm{R}_{\mathrm{L}}<1$ & Favourable \\
$\mathrm{R}_{\mathrm{L}}=0$ & Irreversible \\
\hline
\end{tabular}

Table 4. Values of $\mathrm{R}_{\mathrm{L}}$ of different dye concentration for NBP and NTA-BP

\begin{tabular}{cc}
\hline $\begin{array}{l}\text { Dye concentration of } \mathbf{M B} \\
\text { for NTA-BP }(\mathbf{m g} / \mathbf{L})\end{array}$ & $\mathbf{R}_{\mathbf{L}}$ \\
\hline 100 & 0.015 \\
125 & 0.012 \\
150 & 0.0099 \\
175 & 0.0085 \\
200 & 0.0074 \\
\hline
\end{tabular}

\section{2. 4. Effect of Adsorbent Dosage}

The effect of adsorbent dosage in the adsorption of MB by NTA-BP is shown in Figure 8. It followed the usual pattern of increasing uptake as the adsorbent concentration increased. This corresponds to an increase in active sites for sorption. The uptake of MB by $0.01 \mathrm{~g}$ of NTA-BP increased from $80.2 \%$ to $98.7 \%$ by a two-fold increase in the amount of adsorbent. Thereafter, it remains nearly constant along the increments of adsorbent dosage and the maximum uptake was recorded at $99.5 \%$ by using $0.04 \mathrm{~g}$ of

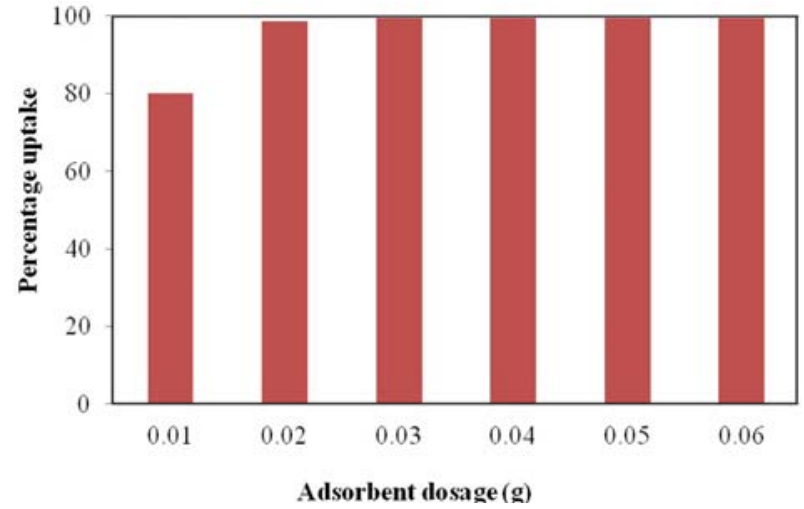

Figure 8. Effect of adsorption dosage on adsorption of MB by NTA-BP (Condition: 0.01, 0.02, 0.03, 0.04, 0.05 and $0.06 \mathrm{~g}$ of adsorbent in $20 \mathrm{~mL}$ of $100 \mathrm{mg} / \mathrm{L}$ dye solution at $150 \mathrm{rpm}$ for 4 hours).

adsorbent. In adsorption process, saturation occurred at certain point at which further increase in adsorbent dosage had little effect on adsorption. This kind of levelling off can be explained in terms of depletion of dye in solution and accumulation of dye molecules on the surface of substrate giving rise to hindering the rest of dye to diffuse inside the substrate matrix. In the removal of Malachite Green dye by using banana pseudo-stem fibers, the authors found that at higher dosage of adsorbent, this has provided more surface area and adsorption sites for the dye molecules. However, the adsorption pattern becomes stable after the surface of adsorbent and the MG dye solution come to equilibrium. $^{27}$

\section{3. Plackett Burman Design and RSM}

Plackett-Burman was carried out by using NTA-BP as the adsorbent and the variables of initial dye concentrations, contact time, adsorbent dosage and $\mathrm{pH}$ were included. This analysis is useful in determining the main factors that have a significant effect in the removal of MB. The re-

Table 5. Plackett-Burman design and results for the removal of MB by NTA-BP

\begin{tabular}{ccccccc}
\hline $\begin{array}{c}\text { Experimental } \\
\text { run }\end{array}$ & $\begin{array}{c}\text { Contact time } \\
\text { (minutes) }\end{array}$ & $\begin{array}{c}\text { Initial concentration } \\
(\mathbf{m g} / \mathbf{L})\end{array}$ & $\begin{array}{c}\text { Variables } \\
\text { Adsorbent } \\
\text { dosage }(\mathbf{g})\end{array}$ & pH & $\begin{array}{c}\text { Observed } \\
\text { response (\%) }\end{array}$ & $\begin{array}{c}\text { Predicted } \\
\text { response }(\%)\end{array}$ \\
\hline 1 & 0.5 & 200 & 0.06 & 10 & 57.2 & 51.9 \\
2 & 0.5 & 100 & 0.06 & 2 & 12.4 & 18.1 \\
3 & 0.5 & 100 & 0.01 & 2 & 1.7 & 8.3 \\
4 & 240 & 100 & 0.01 & 2 & 6.4 & 13.8 \\
5 & 240 & 200 & 0.01 & 10 & 53.8 & 47.6 \\
6 & 0.5 & 200 & 0.06 & 2 & 10.2 & 7.2 \\
7 & 240 & 200 & 0.06 & 2 & 25.6 & 38.6 \\
8 & 0.5 & 200 & 0.01 & 10 & 10.9 & 16.2 \\
9 & 240 & 100 & 0.06 & 10 & 99.3 & 94.1 \\
10 & 240 & 200 & 0.01 & 2 & 6.7 & 2.9 \\
11 & 240 & 100 & 0.06 & 10 & 99.3 & 94.1 \\
12 & 0.5 & 100 & 0.01 & 10 & 10.6 & 27.1 \\
\hline
\end{tabular}


sults and experimental conditions were shown in Table 5. The largest and smallest differences between the experimental and predicted uptakes of dye were $16.52 \%$ and $2.99 \%$, respectively. The differences between the experimental and predicted uptake might due to the involvement of insignificant variable in the analysis. The results of ANOVA were shown in Table 6. From the results, the model is having Prob>F value of 0.0005 and F-value of 21.38. This indicates a significant model. In order to have a significant model, the Prob $>F$ value has to be below 0.05. Among the four variables, only three out of four variables are significant. The significant variables are adsorbent dosage, contact time and solution $\mathrm{pH}$. The effect of initial dye concentration was not significant in the examined range and having Prob $>F$ value of 0.1727 .

The effect of $\mathrm{pH}$ plays an important role in the uptake of MB because this variable affects the degree of ionization and surface properties of NTA-BP. ${ }^{39}$ The amount of available active binding is correlated with the amount of adsorbent dosage, therefore it is also a dominant factor in MB uptake. In dye adsorption process, the contact time affected the percentage uptake of dye due to the three phases which are: (i) rapid attachment of the dye molecules to the surface of the adsorbent, (ii) slower adsorption with the diffusion take place- intra-particle diffusion becomes rate controlling step and (iii) final equilibrium step- the rate of intra-particle diffusion process started to decrease due to very low solute concentration in dye solution. ${ }^{40}$

The influential parameters, contact time, adsorbent dosage and $\mathrm{pH}$ were analysed by using response surface methodology. The modified cubic model which describes the relationship between factors and the uptake of $\mathrm{MB}$ was presented as below:
Percentage uptake $=95.3+25.5 \mathrm{~A}+11.9 \mathrm{~B}+$ $+25.3 \mathrm{C}+11.9 \mathrm{AC}-26.5 \mathrm{~A}^{2}-28.3 \mathrm{C}^{2}$

where $\mathrm{A}=$ Contact time (minutes), $\mathrm{B}=$ Adsorbent dosage (g), $\mathrm{C}=$ solution $\mathrm{pH}$

The regression analysis of ANOVA for the MB uptake was shown in Table 7. Prob $>F$ value of the model is less than 0.0001 and the F-value with 23.03 indicates the model studied was significant. The coefficient of determination, $\mathrm{R}^{2}$ is 0.9540 which is quite close to unity. The relatively high $\mathrm{R}^{2}$ value indicated that there were good agreements between the experimental and predicted values. Meanwhile, the correlation coefficient of variance (C.V.) was recorded as $16.98 \%$. The lesser the value of C.V., the better the precision and consistency of the investigation. ${ }^{41}$ The adequate precision, "Adeq Precision" can determine the ratio of signal to noise. A desirable ratio should have a value of greater than 4 . The ratio of this analysis was determined to 15.38 which showed a satisfactory signal and it is desirable.

Figures 9-11 showed the 3D surface plot that relates the interaction between $\mathrm{pH}$ and contact time (Figure 9), adsorbent dosage and contact time (Figure 10) and $\mathrm{pH}$ and adsorbent dosage (Figure 11). From this kind of response surface plot, the correlation between two important factors and the optimum level of percentage uptake of dye can be easily studied and detected.

Figure 9 showed that the maximum percentage uptake of MB occurred when $\mathrm{pH}$ of dye solution and contact time were both located at highest point in the surface plot. From Figure 10, the percentage uptake of MB dye solution increased when adsorbent dosage and contact time were both increased. And lastly, Figure 11 illustrated that when both of the variables ( $\mathrm{pH}$ and adsorbent dosage) were increased, a higher uptake of MB can be noticed.

Table 6. Regression analysis (ANOVA) of Plackett Burman for the removal of MB from dye solution

\begin{tabular}{|c|c|c|c|c|c|c|}
\hline Source & Degree of freedom & Sum of squares & Mean squares & F-value & Prob $>F$ & Description \\
\hline$\overline{\text { Model }}$ & 4 & 13108.32 & 3277.08 & 21.38 & 0.0005 & Significant \\
\hline Contact time & 1 & 2950.04 & 2950.04 & 19.24 & 0.0032 & Significant \\
\hline Initial concentration & 1 & 353.49 & 353.49 & 2.31 & 0.1727 & Not significant \\
\hline Adsorbent dosage & 1 & 3818.12 & 3818.12 & 24.91 & 0.0016 & Significant \\
\hline $\mathrm{pH}$ & 1 & 5986.67 & 5986.67 & 39.05 & 0.0004 & Significant \\
\hline Residual & 7 & 1073.09 & 153.3 & & & \\
\hline Total & 11 & & & & & \\
\hline
\end{tabular}

Table 7. Regression analysis (ANOVA) for the removal of MB from dye solution

\begin{tabular}{|c|c|c|c|c|c|c|}
\hline Source & Degree of freedom & Sum of squares & Mean squares & F-value & Prob $>F$ & Description \\
\hline Model & 9 & 27558.87 & 3062.1 & 23.03 & $<0.0001$ & Significant \\
\hline Contact time & 1 & 6479.06 & 6479.06 & 48.73 & $<0.0001$ & Significant \\
\hline Adsorbent dosage & 1 & 1433.53 & 1433.53 & 10.78 & 0.0082 & Significant \\
\hline $\mathrm{pH}$ & 1 & 6387.75 & 6387.75 & 48.04 & $<0.0001$ & Significant \\
\hline Residual & 10 & 1329.62 & 132.96 & & & \\
\hline Total & 19 & & & & & \\
\hline
\end{tabular}




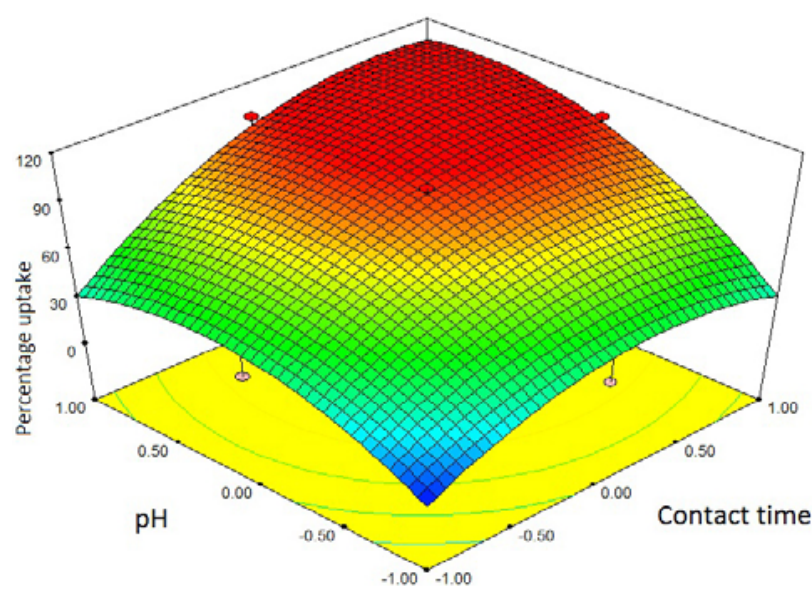

Figure 9. 3D surface plot for uptake of $\mathrm{MB}$ as a function of $\mathrm{pH}$ and contact time.

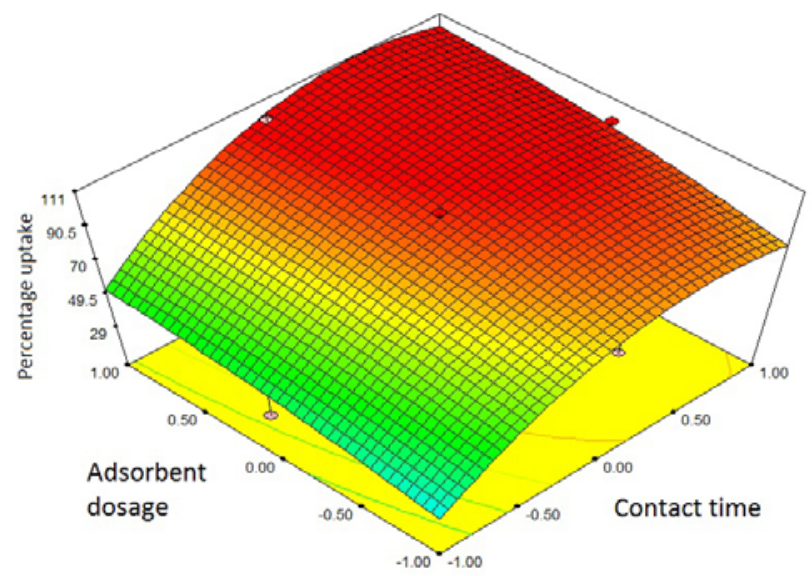

Figure 10. 3D surface plot for uptake of MB as a function of adsorbent dosage and contact time.

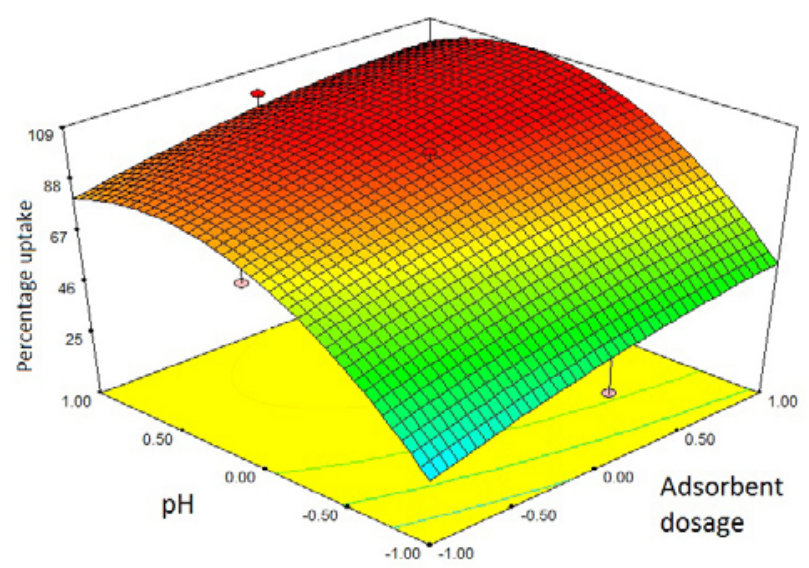

Figure 11. 3D surface plot for uptake of $\mathrm{MB}$ as a function of $\mathrm{pH}$ and adsorbent dosage.

\section{Conclusion}

The present study shows that modification of banana pith with nitrilotriacetic acid (NTA-BP) resulted in the formation of an efficient adsorbent to remove basic dye, Methylene Blue from aqueous environment. The cost of producing NTA-BP is estimated to be threefold cheaper than the price of commercial activated carbon. The results from esterification process on the surface functional groups indicate that carboxyl groups were the major functional groups involved in the adsorption of MB. The maximum adsorption capacity of NTA-BP is $142.86 \mathrm{mg} / \mathrm{g}$. The correlation coefficient, $\mathrm{R}^{2}$ obtained in Langmuir isotherm is 0.992 which is higher than the one obtained in Freundlich isotherm. This indicates the suitability of Langmuir isotherm model in explaining the adsorption behavior of the current study. By using Plackett-Burman, the influential variables were found to be contact time, adsorbent dosage and $\mathrm{pH}$. The interaction between the variables and the optimum level for the maximum uptake was studied by using response surface methodology. Based on the result, under the optimum condition, the percentage uptake of MB can achieved $99.42 \%$ with the compromise of these responses: adsorbent dosage (0.06 $\mathrm{g}$ of NTA-BP), contact time (120 minutes) and $\mathrm{pH}(6)$.

\section{Acknowledgements}

The financial support and research facilities by Universiti Tunku Abdul Rahman via Vote No. 6200/O06 are acknowledged.

\section{References}

1. J. W. Lee, S. P. Choi, R. Thiruvenkatachari, W. G. Shim and H. Moon, Dyes Pigments, 2006, 69, 196-203. http://dx.doi.org/10.1016/j.dyepig.2005.03.008

2. A. Demirbas, J. Hazard. Mater., 2009, 167, 1-9. http://dx.doi.org/10.1016/j.jhazmat.2008.12.114

3. S. T. Ong, S. Y. Tan, E. C. Khoo, S. L. Lee and S. T. Ha, Desalin. Water Treat., 2012, 45, 161-169. http://dx.doi.org/10.1080/19443994.2012.692037

4. L. Levin, L. Papinutti and F. Forchiassin, Bioresour. Technol., 2004, 94, 169-176. http://dx.doi.org/10.1016/j.biortech.2003.12.002

5. G. Palmieri, G. Cennamo and G. Sannia, Enzyme Microb. Technol., 2005, 36, 17-27. http://dx.doi.org/10.1016/j.enzmictec.2004.03.026

6. K. Hunger (Ed.): Industrial Dyes: Chemistry, Properties, Applications, Wiley-VCH, Weinheim, Germany, 2003.

7. G. Crini, Bioresour. Technol., 2006, 97, 1061-1085. http://dx.doi.org/10.1016/j.biortech.2005.05.001

8. A. Nasrullah, H. Khan, A. S. Khan, Z. Man, N. Muhammad, 
M. I. Khan and N. M. A. El-Salam, The Scientific World J., 2015, Article ID 562693, 1-11.

9. D. Pathania, S. Sharma and P. Singh, Arab J Chem., 2015, Article in press.

10. S. Dawood and T. Sen, Water Res., 2012, 46, 1933-1946. http://dx.doi.org/10.1016/j.watres.2012.01.009

11. H. Becker, R. F. D. Matos, J. A. D. Souza, D. D. A Lima, F. T. C. D. Souza and E. Longhinotti, The Electronic J Chem., 2013, 5, 164-170.

12. Y. Bao and G. Zhang, Energy Procedia, 2012, 16, 11411146. http://dx.doi.org/10.1016/j.egypro.2012.01.182

13. O. S. Amuda, A. O. Olayiwola, A. O. Alade, A. G, Farombi and S. A. Adebisi, J Environ. Prot., 2014, 5, 1352-1363. http://dx.doi.org/10.4236/jep.2014.513129

14. B. H. Hameed, A. T. M. Din and A. L. Ahmad, A. L., J. Hazard. Mater., 2006, 141, 819-825.

http://dx.doi.org/10.1016/j.jhazmat.2006.07.049

15. T. Yan and L. Wang, Bioresources, 2013, 8, 4722-4734.

16. N. A. Oladoja, C. O. Aboluwoye and Y. B. Oladimeji, Turk. J Eng. Environ Sci., 2008, 32, 303-312.

17. D. Mohapatra, S. Mishra and N. Sutar, J. Sci. Ind. Res. India, 2010, 69, 323-329.

18. P. W. Araujo and R. G. Brereton, TrAC Trend. Anal. Chem., 1996, 15, 26-31.

19. R. H. Myers and D. C. Montgomery (Eds): Response surface methodology, Wiley-VCH, Weinheim, Germany, 2002.

20. B. Likozar, D. Senica and A. Pavko, AIChe J., 2012, 58, 99-106. http://dx.doi.org/10.1002/aic.12559

21. B. Likozar, D. Senica and A. Pavko, Braz. J. Chem. Eng., 2012, 29, 635-652. http://dx.doi.org/10.1590/S0104-66322012000300020

22. B. Likozar, D. Senica and A. Pavko, Ind. Eng. Chem. Res., 2013, 52, 9247-9258. http://dx.doi.org/10.1021/ie400832p

23. A. Rajendran, M. Thirugnanam and V. Thangavelu, Indian J. Biotechnol., 2007, 6, 467-478.

24. K. Ravikumar, B. Deebika and K. Balu, J. Hazard. Mater., 2005, 122, 75-83.

http://dx.doi.org/10.1016/j.jhazmat.2005.03.008
25. S. T. Ong, S. T. Ha, E. C. Khoo and S. L. Hii, Int. J. Environ. Eng., 2013, 5, 299-309. http://dx.doi.org/10.1504/IJEE.2013.054704

26. R. M. Silverstein, F. X. Webster, D. J. Kiemle (Eds.): Spectrometric identification of organic compounds, Wiley-VCH, Weinheim Germany, 2005, pp. 72-108.

27. N. Gupta, A.K. Kushwaha and M. C. Chattopadhyaya, J. Chem. Pharma. Res., 2011, 3, 284-296.

28. H. Yang, R. Yan, H. Chen, D. H. Lee and C. Zheng, Fuel, 2007, 86, 1781-1788. http://dx.doi.org/10.1016/j.fuel.2006.12.013

29. M. Pishgar, M.E. Yazdanshenas, M. H. Ghorbani and K. Farizadeh, J. App. Chem. Res., 2013, 7, 51-62.

30. S. T. Ong, P. S. Keng and C. K. Lee, Asian. J. Chem., 2011, 24, 2665-2667.

31. K. K. Wong, C. K. Lee, K. S. Low and M. J. Haron, Chemosphere, 2003, 50, 23-28. http://dx.doi.org/10.1016/S0045-6535(02)00598-2

32. I. Langmuir, J. Am. Chem. Soc., 1916, 38, 2221-2295. http://dx.doi.org/10.1021/ja02268a002

33. H. Freundlich, Phys. Chem. Soc., 1906, 40, 1361-1368.

34. D. G. Kinniburgh, Environ. Sci. Technol., 1986, 20, 895904. http://dx.doi.org/10.1021/es00151a008

35. Y. S. Ho, Pol. J. Environ. Stud., 2005, 15, 81-86.

36. X. Chen, Information, 2015, 6, 14-22. http://dx.doi.org/10.3390/info6010014

37. B. Subramanyam, A. Das, Int. J. Environ. Sci. Tech., 2009, 6, 633-640. http://dx.doi.org/10.1007/BF03326104

38. T. W. Weber and R. K. Chakkravorti, Am. Ins. Chem. Eng. J., 1974, 20, 228-238. http://dx.doi.org/10.1002/aic.690200204

39. S. T. Ong and C. K. Seou, Desalin. Water Treat., 2014, 52, 7673-7684. http://dx.doi.org/10.1080/19443994.2013.830684

40. G. L. Dotto and L. A. A. Pinto, J. Hazard. Mater., 2011, 187, 164-170. http://dx.doi.org/10.1016/j.jhazmat.2011.01.016

41. E. C. Khoo, S. T. Ong, Y. T. Hung, S. T. Ha, Desalin. Water Treat., 2013, 51, 7109-7119.

http://dx.doi.org/10.1080/19443994.2013.791774

\section{Povzetek}

Proučevan je bil učinek različnih parametrov kot so $\mathrm{pH}$, kontaktni čas, začetna koncentracija barvila metilen modro (MB) in množina adsorbenta na adsorpcijsko kapaciteto naravnega stržena bananovca (NBP). Ta se je izboljšala z modifikacijo adsorbenta $\mathrm{z}$ nitriloocetno kislino (NTA). Podatke je najbolje opisala Langmuirjeva izotrema. IR spekter obeh adsorbentov NBP in NTA-BP je potrdil prisotnost karboksilnih in hidroksilnih skupin. SEM mikrografi so pokazali, da je površinska struktura NTA-BP pred adsorpcijo bolj gladka kot po njej. Za ugotavljanje pomembnih faktorjev ki vplivajo na adsorpcijo je bil uporabljen princip po Plackett-Burmanu, za določitev medsebojnih vplivov posameznih faktorjev in njihovo optimalno vrednost za maksimalno adsorpcijsko kapaciteto pa je bila uporabljena RSM metoda. Ti rezultati so pokazali, da se maksimalna kapaciteta adsorpcije MB doseže z 0,06 g NTA-BP pri pH 6 in kontaktnem času 120 minut. Eksperimentalno je bilo pri optimalnih pogojih dosežene 99,42\% vrednosti maksimalne kapacitete. 